\title{
3 Research Square Trend of Obesity in The United States During a Decade
}

\section{Alireza Mirahmadizadeh}

Shiraz University of Medical Sciences

Mohammad Hossein Sharifi

Shiraz University of Medical Sciences

Mohammad Aryaie

Shiraz University of Medical Sciences

\section{Zahra Gheibi}

Shiraz University of Medical Sciences

Shahryar Zeighami

Shiraz University of Medical Sciences

Ali Seifi ( $\square$ seifi@uthscsa.edu )

Shiraz University of Medical Sciences

\section{Research Article}

Keywords: Obesity, BMI, Trend, Comorbidities, HCUP-NIS

Posted Date: October 28th, 2021

DOl: https://doi.org/10.21203/rs.3.rs-967484/v1

License: (c) (i) This work is licensed under a Creative Commons Attribution 4.0 International License. Read Full License 


\section{Abstract}

\section{Background and objective}

While obesity prevalence in the United States has increased considerably, its impact on factors such as mortality, comorbidity, and cost have not been extensively analyzed in hospitalized patients. Detailed information on the prevalence of obesity and associated factors among inpatients may help in developing health care policies aimed at reducing mortality, comorbidity, and cost.

\section{Methods}

In this study, data for analysis of inpatient discharges from 2005 to 2015 were obtained from the Health Cost and Utilization Project Nationwide Inpatient Sample (HCUP-NIS) database. Body Mass Index (BMI) of 30 or greater is defined as obesity. Descriptive analysis includes trends of obesity by sex, race, region, location and payer. To classify magnitude of association between obesity and comorbidities, we classified prevalence ratio $(P R)$ to high risk factor $(P R \geq 1.5)$, low risk factor $(P R=<1.5-1.25)$, null $(<1.25$ $>0.8)$ and preventive factor $(P R<0.8)$ based on expert epidemiologists opinion.

\section{Results}

During the study period we reviewed $82,618,702$ discharges with $6,705,774$ obesity for a rate of $8.11 \%$. The percent of obese discharges increased from $4.6 \%$ in 2005 to $11.9 \%$ in 2015 . In all subgroup variables, there was a substantial difference between obesity and non-obesity in hospital patients. Data indicated females had a higher prevalence of hospital discharges with obesity, compared to males. Moreover, Black race had the highest percentage and Asian or Pacific Islander is the lowest in this trend.

\section{Conclusion}

While obesity prevalence in the United States population has slowly increased, there has been a more marked increase in obese patients in the hospital.

\section{Introduction}

While obesity prevalence in the United States has increased considerably $(1,2)$, its impact on factors such as mortality, comorbidity, and cost have not been extensively analyzed in hospitalized patients. Studies have shown that obesity prevalence began to increase substantially in the United States during the 1970s and nearly tripled worldwide between 1975 and 2016 (3) Detailed information on the prevalence of obesity and associated factors among inpatients may help in developing health care policies aimed at reducing mortality, comorbidity, and cost.

Obesity increases the risk of non-communicable diseases (NCDs) by its association with numerous comorbidities (4). The "Global Action Plan" of WHO will contribute to nine worldwide NCD objectives to be achieved by 2025 , including halting worldwide obesity growth and decreasing premature death from 
NCDs by 25 percent (4). The deleterious effects of excess body weight on chronic disease such as diabetes, hypertension, coronary artery disease, congestive heart disease, chronic kidney disease, chronic obstructive pulmonary disease, etc. have been well documented. Although data revealed a global upsurge in comorbidity related to obesity (5), comparison of the prevalence ratio of comorbidity was not well explored among inpatients. Detailed data on the association of comorbidity and obesity among inpatients can support priority actions and the objectives of the NCDs to be achieved by 2025 .

Obesity is not just a health problem, but also a socioeconomic issue. The estimation of the Global BMI Mortality Collaboration (GBMC) showed that the relationship of overweight and obesity with mortality and burden of disease differs across different populations(6). Hospitalization-related obesity and mortality is a significant contributor to increasing healthcare expenses and burden of diseases $(7,8)$. Consequently, the increasing burden of obesity clearly decreases economic output in developed and developing countries. Furthermore, studies have shown that annual hospital care expenditure increased by an average of 5.5 percent between 2008 and 2012 (9). A growing proportion of health care costs across all forms of payers in the United States is associated with obesity (10). However, sparse data analysis exists regarding hospitalization-related obesity costs. Decreasing obesity-related hospital costs could be one a target and metric of comprehensive strategic plans in obesity initiatives may help in developing medical strategies and health care policies aimed at reducing mortality, comorbidity, and cost. This study analyzes data from the Healthcare Cost and Utilization Project (HCUP) to identify trends in obese hospitalized patients and address the association between obesity, mortality, and comorbidity in the United States.

\section{Methods}

\section{Data Source}

The Healthcare Cost and Utilization Project-Nationwide Inpatient Sample (HCUP-NIS) represents approximately $20 \%$ of all hospitalizations across the United States and is anonymized and de-identified. The database is based on every discharge and includes clinical variables on all diagnoses and procedures, and is considered the most accurate and precise data on inpatient care and outcomes in the United States (3).

In this study, data for analysis of over 82,000,000 inpatient discharges from 2005 to 2015 were obtained from the Health Cost and Utilization Project Nationwide Inpatient Sample (HCUP-NIS) database. (1, 2). All hospitalized patients all ages who were diagnosed with Obesity on HCUP-NIS between 2005 and 2015 were included in this analysis. In HCUP-NIS database, Body Mass Index (BMI) of 30 or greater is defined as obesity and is considered as comorbidity.

Demographic information including age, gender, race, ethnicity (White, Black, Hispanic, Asian or Pacific islanders and Native American race, and other), insurance type, and residential region abstracted from HCUP-NIS were used plus the comorbidities using International Classification of Disease, 9th Revision, 
Clinical Modification (ICD-9-CM). The Institutional Review Board of University of Texas Health at San Antonio exempted this analysis from full review.

\section{Statistical Analysis}

All analyses were carried out using Stata version 12.0 software (Stata, College Station, TX, USA). To estimate measure of association, we used prevalence ratio as proxy for relative risk, because we faced with a cross-sectional data. To classify magnitude of association between obesity and comorbidities, we classified prevalence ratio (PR) to high risk factor ( $P R \geq 1.5)$, low risk factor ( $P R=<1.5-1.25)$, null $(<1.25$ $>0.8)$ and preventive factor $(P R<0.8)$ based on expert epidemiologists opinion. Admission disease severity categorized to five tiers including minor likelihood of dying, moderate likelihood of dying, major likelihood of dying, extreme likelihood of dying, and no class specified risk of dying based on International Classification of Diseases, Ninth Revision, Clinical Modification (ICD-9-CM) codes for four leading risk factors in the United States Nationwide Inpatient Sample (NIS). More information on HCUP-NIS is available in: https://www.hcup-us.ahrq.gov/nisoverview.jsp.

Statistical analysis was divided 3 sections: descriptive, analytic and forecasting. Descriptive analysis includes trends of obesity by sex, race, region, location and payer. Analytical statistic includes comparison of obesity prevalence in some demographic and non-demographic variables. Also, we compared probability of disease severity and selected some comorbidities in obese vs. non-obese patients. Forecasting of obesity prevalence among inpatients was done by ARIMA model for 36 months after 2015. All differences between estimates noted in the text are statistically significant at the .001 level.

\section{Results}

During the study period we reviewed $82,618,702$ discharges with $6,705,774$ obesity for a rate of $8.11 \%$. The subject studies were mainly female $58 \%$, with the mean age of 48.2 years old and mainly white (66.15\%). Reviewing the age groups, 50-65 years-old (34.47\%) and $>65$ years -old (30.33\%) age groups were the highest prevalence of obesity among hospitalized patients. The percent of obese discharges increased from $4.6 \%$ in 2005 to $11.9 \%$ in 2015 . The demographic characteristics of subjects is provided in Table1. 
Table 1

Demographic characteristics of obesity discharges in United States, 2005-2015

\begin{tabular}{|c|c|c|c|c|c|}
\hline \multirow{3}{*}{$\begin{array}{l}\text { Demographic } \\
\text { characteristics }\end{array}$} & \multirow[t]{3}{*}{ Subgroup } & \multicolumn{2}{|l|}{ Population } & \multirow{2}{*}{\multicolumn{2}{|c|}{$\begin{array}{l}\text { Prevalence of } \\
\text { obesity }\end{array}$}} \\
\hline & & \multirow{2}{*}{ No. } & \multirow{2}{*}{$\%$} & & \\
\hline & & & & $\%$ & p.value \\
\hline \multirow[t]{2}{*}{ Gender } & Female & $47,991,543$ & 58.09 & 8.8 & \multirow[t]{2}{*}{$<0.001$} \\
\hline & Male & $34,627,159$ & 41.91 & 7.16 & \\
\hline \multirow[t]{6}{*}{ Age group } & $0-5$ & $11,407,918$ & 13.5 & 0.07 & \multirow[t]{6}{*}{$<0.001$} \\
\hline & $6-18$ & $2,736,780$ & 3.24 & 1.33 & \\
\hline & $19-35$ & $14,304,090$ & 16.93 & 12.79 & \\
\hline & $36-50$ & $11,604,801$ & 13.77 & 21.02 & \\
\hline & $51-65$ & $16,287,568$ & 19.25 & 34.47 & \\
\hline & $>65$ & $28,133,414$ & 33.3 & 30.33 & \\
\hline \multirow[t]{6}{*}{ Race } & White & $46,383,331$ & 66.15 & 8.63 & \multirow[t]{6}{*}{$<0.001$} \\
\hline & Black & $10,082,136$ & 14.38 & 10.55 & \\
\hline & Hispanic & $8,847,777$ & 12.62 & 6.79 & \\
\hline & $\begin{array}{l}\text { Asian or Pacific } \\
\text { Islander }\end{array}$ & $1,890,151$ & 2.7 & 3.07 & \\
\hline & Native American & 478,363 & 0.68 & 8.65 & \\
\hline & Other & $2,436,647$ & 3.48 & 5.92 & \\
\hline \multirow[t]{4}{*}{ Region of hospital } & Northeast & $15,606,295$ & 18.85 & 6.89 & \multirow[t]{4}{*}{$<0.001$} \\
\hline & Midwest & $18,649,619$ & 22.53 & 8.96 & \\
\hline & South & $32,164,040$ & 38.86 & 8.31 & \\
\hline & West & $16,352,521$ & 19.76 & 7.87 & \\
\hline \multirow{2}{*}{$\begin{array}{l}\text { Hospital location } \\
\text { (2005-2011) }\end{array}$} & Rural & $6,891,100$ & 12.41 & 6.26 & \multirow[t]{2}{*}{$<0.001$} \\
\hline & Urban & $48,625,324$ & 87.59 & 6.86 & \\
\hline
\end{tabular}

In all subgroup variables, there was a substantial difference between obesity and non-obesity in hospital patients. Data indicated that females had a higher prevalence of hospital discharges with obesity, compared to males. In addition, increasing the age associated with increasing the prevalence of hospital discharges with obesity $(p=<0.001)$. Black, Native American and white races had the highest prevalence hospitalized patients discharges with obesity in United States $(P<0.001)$. 
Figure 1 illustrate trend of obesity proportion by gender among hospitalized patients in United States, 2005-16. The figure shows that there has been a marked increase in hospitalized male and female obese patients in United States. Data revealed that the total proportion of people hospitalized with obesity was approximately $12 \%$ in 2015 .

Reviewing the ethnicity showed that proportion of hospitalized obese patients raised in White, Black, Hispanic, Asian or Pacific islanders and Native American race during the study period. As we can see, black race had the highest percentage and Asian or Pacific Islander is the lowest in this trend $(P<0.001)$, (Figure 2).

Analyzing the trend of obesity by rural and urban hospital locations among hospitalized patients, showed a gradual increase in both type hospitals. However, the hospitalization of rural obese patients was statistically less than the urban obese discharges $(P<0.001)$, (Figure 3 ).

\section{Forecast Prediction}

The trend of obesity among hospitalized patients in the United States for the years 2005-2015 has been a markedly increased since 2005-2015 and with this pattern, the trend of obesity forecast among hospitalized patients is expected to increase in next years, (Figure 4 ).

\section{Severity Of Diseases And Mortality}

We dichotomized the study subjects to Obese and non-Obese and compared the frequency of admission disease severity, risk of dying and mortality. Analyzing the array of "admission disease severity" for the likelihood of dying more than moderate likelihood, the discharges with obesity had $85.8 \%$ among obese patient at admission duration, compared to $61.83 \%$ in non-obese patients. Moreover, the overall mild, medium and high the risk of dying in obese hospitalized patients was $47.7 \%$ compared to $38.82 \%$ in nonobese hospitalized patients. Interestingly, percent of mortality between obese and non-obese hospitalized patients were $1.43 \%$ and $1.99 \%$ respectively $(p<0.001)$. (Table 2 ). 
Table 2

comparison of frequency severity conditions, risk of dying and mortality between obese and non-obese hospitalized patients in United States, 2005-14.

\begin{tabular}{|c|c|c|c|c|c|c|c|}
\hline \multirow[t]{3}{*}{ Variables } & \multirow[t]{3}{*}{ Conditions } & \multicolumn{5}{|c|}{ Frequency and prevalence of conditions among } & \multirow[t]{3}{*}{ P.Value } \\
\hline & & \multicolumn{2}{|c|}{$\begin{array}{l}\text { Obese } \\
(n=6,705,774)\end{array}$} & \multicolumn{2}{|c|}{$\begin{array}{l}\text { Non-obese } \\
(n=76,066,701)\end{array}$} & \multirow{2}{*}{$\begin{array}{l}\text { (obese/non- } \\
\text { obese) } \\
\text { PR }\end{array}$} & \\
\hline & & No. & $\%$ & No. & $\%$ & & \\
\hline \multirow{5}{*}{$\begin{array}{l}\text { Admission } \\
\text { disease } \\
\text { severity }\end{array}$} & $\begin{array}{l}\text { No class } \\
\text { specified }\end{array}$ & 1,946 & 0.03 & 70,314 & 0.09 & 0.33 & \multirow[t]{5}{*}{$<0.001$} \\
\hline & $\begin{array}{l}\text { Minor } \\
\text { likelihood of } \\
\text { dying }\end{array}$ & 950,697 & 14.18 & $28,960,157$ & 38.07 & 0.32 & \\
\hline & $\begin{array}{l}\text { Moderate } \\
\text { likelihood of } \\
\text { dying, }\end{array}$ & $3,146,081$ & 46.92 & $27,217,873$ & 35.78 & 1.37 & \\
\hline & $\begin{array}{l}\text { Major } \\
\text { likelihood of } \\
\text { dying, }\end{array}$ & $2,101,700$ & 31.34 & $15,428,205$ & 20.28 & 1.55 & \\
\hline & $\begin{array}{l}\text { Extreme } \\
\text { likelihood of } \\
\text { dying }\end{array}$ & 505,350 & 7.54 & $4,390,152$ & 5.77 & 1.31 & \\
\hline \multirow{4}{*}{$\begin{array}{l}\text { Risk of } \\
\text { dying }\end{array}$} & Low & $3,505,106$ & 52.27 & $46,474,940$ & 61.1 & 0.86 & \multirow[t]{4}{*}{$<0.001$} \\
\hline & Mild & $1,797,467$ & 26.8 & $16,861,731$ & 22.17 & 1.21 & \\
\hline & Medium & $1,024,015$ & 15.27 & $9,224,408$ & 12.13 & 1.26 & \\
\hline & High & 377,240 & 5.63 & $3,435,308$ & 4.52 & 1.25 & \\
\hline \multirow{2}{*}{$\begin{array}{l}\text { Died in } \\
\text { hospital }\end{array}$} & Yes & 96,012 & 1.43 & $1,512,195$ & 1.99 & 0.72 & \multirow[t]{2}{*}{$<0.001$} \\
\hline & No & $6,606,818$ & 98.57 & $74,510,627$ & 98.01 & - & \\
\hline
\end{tabular}

When analyzed the association between obesity and selected cofactors with in-hospital mortality, the data showed significant differences in all predictors. In this respect, there was a $24 \%$ reduction of inhospital death probability among obese hospitalized patients. Data also indicated that any comorbidity could increase the probability of in-hospital deaths among obese hospitalized patients, but uncomplicated diabetes and hypertension had a protective effect in the probability of in-hospital deaths. (Table 3). 
Table 3

Association (crude and adjusted OR using multivariate logistic regression) between obesity and selected cofactors with in-hospital death in United States, 2005-2015

\begin{tabular}{|llll|}
\hline Predictors & Crude OR & Adjusted OR $(95 \% \mathrm{Cl})$ & P.Value \\
\hline Obesity & 0.72 & $0.7618618(0.756499-0.7672627)$ & $<0.001$ \\
\hline Age & 1.47 & $1.039265(1.039158-1.039373)$ & $<0.001$ \\
\hline Alcohol & 0.78 & $1.298812(1.288162-1.309549)$ & $<0.001$ \\
\hline Sex (female =1) & 1.42 & $0.7431264(0.7405718-0.7456899)$ & $<0.001$ \\
\hline Race (white vs. non-white) & 1.39 & $1.052353(1.050731-1.053977)$ & $<0.001$ \\
\hline Any comorbidity & 5.34 & $3.150981(3.12936-3.172752)$ & $<0.001$ \\
\hline Diabetes (uncomplicated) & 1.46 & $0.9881986(0.9839283-0.9924874)$ & $<0.001$ \\
\hline Diabetes (complicated) & 1.43 & $1.038142(1.030006-1.046341)$ & $<0.001$ \\
\hline Hypertension & 1.51 & $0.5143692(0.5124861-0.5162592)$ & $<0.001$ \\
\hline Constant & - & $0.0011183(0.0011085-0.0011283)$ & $<0.001$ \\
\hline
\end{tabular}

The mean age of obese patients was 55.49 years old ( \pm SD16.72), while the mean age of admission among non-obese patients was 47.6 years old \pm 28.5 ( $p<0.001)$. Obese patients had significantly higher hospital charges, the mean total charge of obese patients was $\$ 43387.47 \pm 65,196.81$ per discharge though the mean total charge among non-obese patients was \$31410.79 ( \pm SD 59,992.12), $(p<0.001)$. That means that the total charges of obese patients at admission period was approximately $25 \%$ higher than non-obese inpatients. In addition, the average hospital length of stay of obese patients was 5.14 days ( \pm SD 6.41), although the average hospital stay among non-obese patients was 4.54 ( \pm SD 6.82), $(p<0.001$. Detailed provide in Table 4.

Table 4

Comparison of age, total charge and hospital stay between obese and non-obese hospitalized patients in United States, 2005-15.

\begin{tabular}{|llllllll|}
\hline \multirow{2}{*}{$\begin{array}{l}\text { Age and Hospital } \\
\text { related variables }\end{array}$} & \multicolumn{2}{l}{ Obese $(\boldsymbol{n = 6 , 7 0 5 , 7 7 4 )}$} & \multicolumn{4}{c|}{ Non-obese $(\boldsymbol{n}=76,066,701)$} & \multirow{2}{*}{ p.value } \\
\cline { 2 - 8 } & Mean & SD & SE & Mean & SD & SE & \\
\hline Age (year) & 55.49 & 16.72 & 0.006 & 47.6 & 28.5 & 0.003 & $<0.001$ \\
\hline Total charge (\$) & $43,387.47$ & $65,196.81$ & 25.4 & $31,410.79$ & $59,992.12$ & 6.92 & $<0.001$ \\
\hline $\begin{array}{l}\text { Length of } \\
\begin{array}{l}\text { Hospital Stay } \\
\text { (days) }\end{array}\end{array}$ & 5.14 & 6.41 & 0.002 & 4.54 & 6.82 & 0.0007 & $<0.001$ \\
\hline
\end{tabular}

Reviewing the prevalence of medical comorbidities in obese patients, based on the tiers of prevalence ratio( PR), obese patients had a higher PR range of 1.61 to 2.9 with comorbidities such as diabetes with 
chronic complications, uncomplicated diabetes, pulmonary circulation disorders, depression, congestive heart failure, chronic pulmonary disease, hypertension, complicated and uncomplicated, renal failure, hypothyroidism, psychoses, and liver disease. (Table 5). 
Table 5

Comparison of prevalence of comorbidity between obese and non-obese hospitalized patients in United States, 2005-14

\begin{tabular}{|c|c|c|c|c|c|c|c|}
\hline \multirow[t]{3}{*}{ Comorbidities } & \multicolumn{4}{|c|}{$\begin{array}{l}\text { Frequency and prevalence of Comorbidity } \\
\text { among obese and non- obese }\end{array}$} & \multirow{2}{*}{\multicolumn{2}{|c|}{$\begin{array}{l}\text { Measure of } \\
\text { association } \\
\text { (obese/non-obese) }\end{array}$}} & p.value \\
\hline & \multicolumn{2}{|c|}{$\begin{array}{l}\text { Obese } \\
(n=6,705,774)\end{array}$} & \multicolumn{2}{|c|}{$\begin{array}{l}\text { Non-obese } \\
(n=76,066,701)\end{array}$} & & & \\
\hline & No. & $\%$ & No. & $\%$ & Prevalenc & & \\
\hline $\begin{array}{l}\text { Diabetes with chronic } \\
\text { complications }\end{array}$ & 594,286 & 8.86 & $2,275,081$ & 2.99 & $\begin{array}{l}\text { High risk } \\
\text { factor }\end{array}$ & 2.96 & $<0.001$ \\
\hline $\begin{array}{l}\text { Diabetes, } \\
\text { uncomplicated }\end{array}$ & $2,229,883$ & 33.25 & $10,066,036$ & 13.23 & & 2.51 & $<0.001$ \\
\hline $\begin{array}{l}\text { Pulmonary } \\
\text { circulation disorders }\end{array}$ & 209,695 & 3.13 & 970,900 & 1.28 & & 2.45 & $<0.001$ \\
\hline Depression & 930,097 & 13.87 & $5,777,848$ & 7.6 & & 1.83 & $<0.001$ \\
\hline $\begin{array}{l}\text { Congestive heart } \\
\text { failure }\end{array}$ & 768,644 & 11.46 & $4,827,295$ & 6.35 & & 1.80 & $<0.001$ \\
\hline $\begin{array}{l}\text { Chronic pulmonary } \\
\text { disease }\end{array}$ & $1,691,538$ & 25.23 & $10,745,692$ & 14.13 & & 1.79 & $<0.001$ \\
\hline $\begin{array}{l}\text { Hypertension, } \\
\text { complicated and } \\
\text { uncomplicated }\end{array}$ & $4,206,992$ & 62.74 & $27,843,850$ & 36.6 & & 1.71 & $<0.001$ \\
\hline Renal failure & 893,822 & 13.33 & $6,121,578$ & 8.05 & & 1.66 & $<0.001$ \\
\hline Hypothyroidism & 889,979 & 13.27 & $6,139,082$ & 8.07 & & 1.64 & $<0.001$ \\
\hline Psychoses & 363,240 & 5.42 & $2,525,686$ & 3.32 & & 1.63 & $<0.001$ \\
\hline Liver disease & 222,246 & 3.31 & $1,560,164$ & 2.05 & & 1.61 & $<0.001$ \\
\hline $\begin{array}{l}\text { Rheumatoid } \\
\text { arthritis/collagen } \\
\text { vascular diseases }\end{array}$ & 186,229 & 2.78 & $1,488,717$ & 1.96 & $\begin{array}{l}\text { Low risk } \\
\text { factor }\end{array}$ & 1.42 & $<0.001$ \\
\hline Deficiency anemia & $1,182,241$ & 17.63 & $9,624,070$ & 12.65 & & 1.39 & $<0.001$ \\
\hline $\begin{array}{l}\text { Peripheral vascular } \\
\text { disorders }\end{array}$ & 383,986 & 5.73 & $3,268,938$ & 4.3 & & 1.33 & $<0.001$ \\
\hline $\begin{array}{l}\text { Fluid and electrolyte } \\
\text { disorders }\end{array}$ & $1,493,062$ & 22.27 & $13,415,725$ & 17.64 & & 1.26 & $<0.001$ \\
\hline Coagulopathy & 259,667 & 3.87 & $2,526,206$ & 3.32 & Neutral & 1.17 & $<0.001$ \\
\hline $\begin{array}{l}\text { Valvular heart } \\
\text { disease }\end{array}$ & 206,757 & 3.08 & $2,162,874$ & 2.84 & & 1.08 & $<0.001$ \\
\hline Chronic blood loss & 149,691 & 2.23 & $1,612,317$ & 2.12 & & 1.05 & $<0.001$ \\
\hline
\end{tabular}




\begin{tabular}{|c|c|c|c|c|c|c|c|}
\hline Paralysis & 135,144 & 2.02 & $1,501,853$ & 1.97 & & 1.03 & $<0.001$ \\
\hline $\begin{array}{l}\text { Peptic ulcer disease } \\
\text { excluding bleeding }\end{array}$ & 1,842 & 0.03 & 21,541 & 0.03 & & 1.00 & 0.209 \\
\hline Drug abuse & 224,264 & 3.34 & $2,571,933$ & 3.38 & & 0.99 & $<0.001$ \\
\hline $\begin{array}{l}\text { Other neurological } \\
\text { disorders }\end{array}$ & 374,159 & 5.58 & $4,497,321$ & 5.91 & & 0.94 & $<0.001$ \\
\hline Weight loss & 195,607 & 2.92 & $2,507,071$ & 3.3 & & 0.88 & $<0.001$ \\
\hline Alcohol abuse & 197,845 & 2.95 & $2,795,843$ & 3.68 & \multirow{5}{*}{$\begin{array}{l}\text { Preventive } \\
\text { Factors }\end{array}$} & 0.80 & $<0.001$ \\
\hline Lymphoma & 30,766 & 0.46 & 472,841 & 0.62 & & 0.74 & $<0.001$ \\
\hline $\begin{array}{l}\text { Solid tumor without } \\
\text { metastasis }\end{array}$ & 80,847 & 1.21 & $1,245,523$ & 1.64 & & 0.74 & $<0.001$ \\
\hline Metastatic cancer & 75,653 & 1.13 & $1,355,373$ & 1.78 & & 0.63 & $<0.001$ \\
\hline AIDS & 6,471 & 0.1 & 155,299 & 0.2 & & 0.50 & $<0.001$ \\
\hline
\end{tabular}

\section{Discussion}

Our study showed that the prevalence of obesity in United States hospital discharges is 8.11 percent, with a growing trend among males and females, all races, and both rural and urban areas. In addition, while the overall low, medium, and high risk of death in obese hospitalized patients was higher than in nonobese hospitalized patients, the overall mortality in non-obese hospitalized patients was higher. Furthermore, the total mean charge, admission period, and average hospital stay were greater than in obese hospitalized patients. Interestingly, analysis showed that the risk of death in hospital among obese hospitalized patients was decreased approximately $24 \%$, compared to non-obese inpatients. However, evidence showed that any comorbidity could increase the likelihood of hospital death among obese hospitalized patients, but uncomplicated diabetes and hypertension had protective role with regard to inhospital mortality. Data revealed that obese hospitalized patients had the highest rates of comorbidities such as diabetes with chronic complications, uncomplicated diabetes, pulmonary circulation disorders, depression, congestive heart failure, chronic pulmonary disease, hypertension, renal failure, hypothyroidism, psychoses, and liver disease.

Although the acceleration in obesity prevalence slowed in the general United States population since 2007 (11), it has increased among hospitalized patients and is expected to rise in coming years. Consequently, we expect increased length of hospital stay and hospital costs.

Obesity is an important risk factor for mortality, associated with metabolic syndrome, type 2 diabetes mellitus, hypertension, hyperlipidemia, and certain types of cancer. In addition, numerous studies have analyzed obesity as an independent risk factor for all-cause mortality. However, few studies have 
compared admission disease severity, risk of dying, and mortality between obese and non-obese hospital patients. Based on the findings of our study, although the total moderate, major, and extreme likelihood of death based on admission disease severity was higher in obese individuals, in-hospital mortality was higher in non-obese patients. It is difficult to explain this result, but it might be related to little data about the relationship between obesity and chronic disease outcomes, especially among hospitalized individuals (9). Another possible explanation for this outcome is the significant weight loss that comes with progression of many severe chronic diseases associated with obesity. For example, in patients over 65 years of age, increases in severe chronic diseases are associated with increased rates of sarcopenic obesity defined by changes in body composition, such as high body fat, reduced muscle mass, and possible weight loss $(12,13)$. Furthermore, a previous study found obesity in hospitalized sepsis patients to be significantly associated with a $16 \%$ decrease in mortality (14). Such findings add to the emerging evidence base about the paradox of obesity. This is an important issue for future research.

Day-to-day expenditures of hospital care are important components for the overall budget of a health care system. The findings of our research indicate that, although the mean age of non-obese hospitalized patients was higher than that of obese patients, length of stay and mean total charges were higher among obese patients. Other studies have shown that higher BMI is associated with increased length of stay (9). Per the HCUP database, the average cost of a single hospitalization in the United States is $\$ 10,700$ (9). Obesity is an important risk factor for the conditions that collectively account for more than $70 \%$ of all hospital costs (9). Furthermore, in 2004 , the mean length of stay in U.S. hospitals with comorbid obesity was 4.9 days. Since that time, average length of stay has increased by more than five days, with an associated increase in cost.

Obesity-related comorbidites lead to increase mortality and health care expenditures. Our findings revealed that all studied comorbidities, with the exception of uncomplicated diabetes and hypertension, increase the probability of in-hospital death among obese hospitalized patients. Some comorbidities were particularly prevalent in obese hospitalized patients compared to non-obese patients, including diabetes, pulmonary circulation disorders, depression, congestive heart failure, chronic pulmonary disease, hypertension, renal failure, hypothyroidism, psychosis, and liver disease. These results were largely consistent with those of a recent APNA study (15) and a WV Padula study(16). This large study indicated that increasing $\mathrm{BMI}$ is associated with glucose intolerance, dyslipidemia, hypertension, type 2 diabetes, kidney failure, osteoarthritis, asthma, heart failure, severe mental disorders, and chronic obstructive pulmonary disease (15). Obesity complications such as depression and cardiovascular disease have also been shown to adversely affect quality of life (17) and increase both domestic health spending and medical expenses $(16,18)$. Greater understanding of the financial implications of obesity and its associated comorbidities could aid in developing programs and policies to curb healthcare spending.

\section{Conclusion}

While obesity prevalence in the United States population has slowly increased, there has been a more marked increase in obese patients in the hospital. With analysis of this large and nationally 
representative sample of over $82,000,000$ United States hospital discharges, data revealed mean total charges for obsess patients was approximately $25 \%$ higher compared to non-obese patients. Obesity was also significantly associated with severity of admission disease and risk of dying. Surprisingly, the inhospital mortality was lower in non-obese patient than in obese patients. With the exception of uncomplicated diabetes and hypertension, all studied comorbidities increased risk of in-hospital death among obese patients. The most prevalent comorbidities among obese hospitalized patients were diabetes with chronic complications, uncomplicated diabetes, pulmonary circulation disorders, depression, congestive heart failure, chronic pulmonary disease, hypertension, renal failure, hypothyroidism, psychoses, and liver disease. Our findings add to the growing body of literature on the risk of mortality, comorbidities, and costs for obese hospitalized patients. Such information could aid health care administrators and policymakers in implementing quality improvement and cost-saving measures for patients. Future studies on this topic are therefore recommended.

\section{Declarations}

\section{Acknowledgment}

Not applicable

\section{Authors' contributions}

AM conceived the study; MHS, MA, and ZGH contributed to analysis of data. AM, SHZ, and AS wrote the main manuscript text including tables and figures. All authors reviewed the manuscript. AS approved the manuscript.

\section{Funding}

Not applicable

\section{Availability of data and materials}

The datasets used and/or analysed during the current study available from the corresponding author on reasonable request.

\section{Ethics approval and consent to participate}

The database is based on every discharge and includes clinical variables on all diagnoses and procedures. Based on nature of this study, the informed consent was waived. Furthermore, all methods were performed in accordance with relevant guidelines and regulations. The Institutional Review Board at University of Texas Health Science Center at San Antonio, excepted HCUP database from full review.

\section{Consent for publication}

Not applicable 


\section{Competing interests}

The authors declare that they have no competing interests.

\section{Author details}

${ }^{1}$ Non-Communicable Diseases Research Center, Shiraz University of Medical Sciences, Shiraz, Iran, Alireza, Mirahmadizadeh. ${ }^{2}$ Research Center for Traditional Medicine and History of Medicine, Shiraz University of Medical Sciences, Shiraz, Iran, Mohammad Hossein, Sharifi. ${ }^{3}$ Department of Epidemiology, School of Health, Shiraz University of Medical Sciences, Shiraz, Iran, Mohammad, Aryaie. ${ }^{4}$ Shiraz University of Medical Sciences, Department of Epidemiology, Shiraz, Iran, Zahra, Gheibi. ${ }^{5}$ Department of Urology, Shiraz University of Medical Sciences, Shiraz, Iran, Shahryar, Zeighami. ${ }^{6}$ University of Texas Health Science Center at San Antonio, Ali Seifi.

\section{References}

1. Hales CM, Carroll MD, Fryar CD, Ogden CL. Prevalence of obesity among adults and youth: United States, 2015-2016. 2017.

2. Flegal KM, Carroll MD, Kit BK, Ogden CL. Prevalence of obesity and trends in the distribution of body mass index among US adults, 1999-2010. Jama. 2012;307(5):491-7.

3. Rodgers A, Woodward A, Swinburn B, Dietz WH. Prevalence trends tell us what did not precipitate the US obesity epidemic. The Lancet Public Health. 2018;3(4):e162-e3.

4. https://apps.who.int/iris/handle/10665/312281 WHOGNthtrioWHO.

5. Eleazu CO, OMAR N, Lim OZ, Yeoh BS, Mohamed M, Hazlina N. Obesity and comorbidity: could simultaneous targeting of esRAGE and sRAGE be the panacea? Frontiers in Physiology. 2019;10:787.

6. Flegal KM, loannidis JP. A meta-analysis but not a systematic review: an evaluation of the Global BMI Mortality Collaboration. Journal of clinical epidemiology. 2017;88:21-9.

7. Hossain M, Amin A, Paul A, Qaisar H, Akula M, Amirpour A, et al. Recognizing obesity in adult hospitalized patients: a retrospective cohort study assessing rates of documentation and prevalence of obesity. Journal of clinical medicine. 2018;7(8):203.

8. Klatsky AL, Zhang J, Udaltsova N, Li Y, Tran HN. Body mass index and mortality in a very large cohort: is it really healthier to be overweight? The Permanente Journal. 2017;21.

9. Akinyemiju T, Meng Q, Vin-Raviv N. Association between body mass index and in-hospital outcomes: Analysis of the nationwide inpatient database. Medicine. 2016;95(28).

10. Biener A, Cawley J, Meyerhoefer $C$. The impact of obesity on medical care costs and labor market outcomes in the US. Clinical chemistry. 2018;64(1):108-17.

11. Weiss AJ, Elixhauser A. Obesity-Related Hospitalizations, 2004 Versus 2009: Agency for Healthcare Research and Quality; 2012.

12. Newman A. Obesity in older adults. The Online Journal of Issues in Nursing. 2009;14(1). 
13. Oliveira EA, Cheung WW, Toma KG, Mak RH. Muscle wasting in chronic kidney disease. Pediatric Nephrology. 2018;33(5):789-98.

14. Nguyen AT, Tsai C-I, Hwang L-y, Lai D, Markham C, Patel B. Obesity and mortality, length of stay and hospital cost among patients with sepsis: a nationwide inpatient retrospective cohort study. PLoS One. 2016;11(4):e0154599.

15. Martin-Rodriguez E, Guillen-Grima F, Marti A, Brugos-Larumbe A. Comorbidity associated with obesity in a large population: The APNA study. Obesity research \& clinical practice. 2015;9(5):435-47.

16. Padula WV, Allen RR, Nair K. Determining the cost of obesity and its common comorbidities from a commercial claims database. Clinical obesity. 2014;4(1):53-8.

17. Garbarino S, Lanteri P, Durando P, Magnavita N, Sannita W. Co-morbidity, mortality, quality of life and the healthcare/welfare/social costs of disordered sleep: a rapid review. International journal of environmental research and public health. 2016;13(8):831.

18. Khaodhiar L, McCowen KC, Blackburn GL. Obesity and its comorbid conditions. Clinical cornerstone. 1999;2(3):17-31.

\section{Figures}

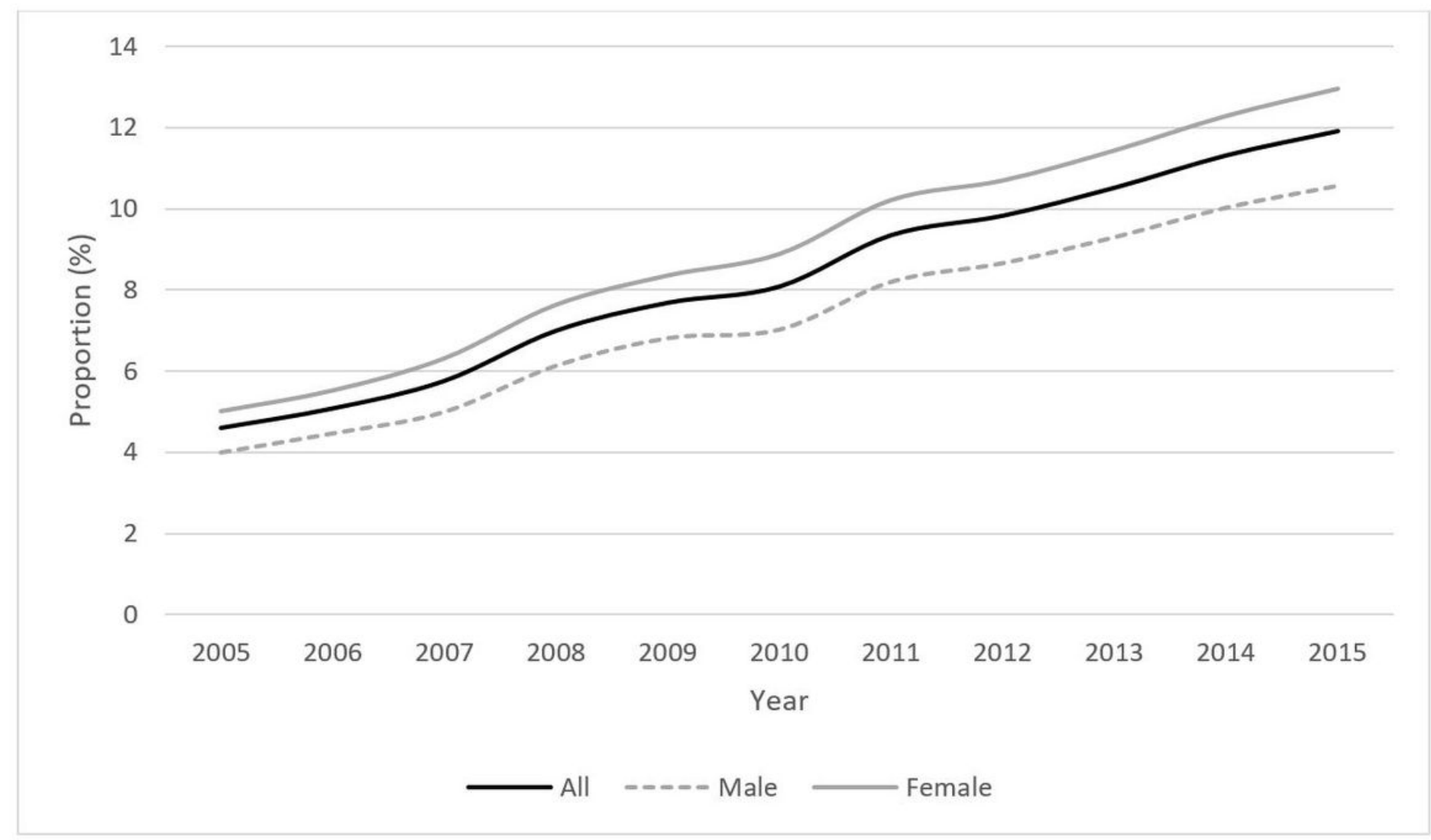

\section{Figure 1}

Trent of obesity proportion by gender amongst hospitalized patients in United States, 2005-15 


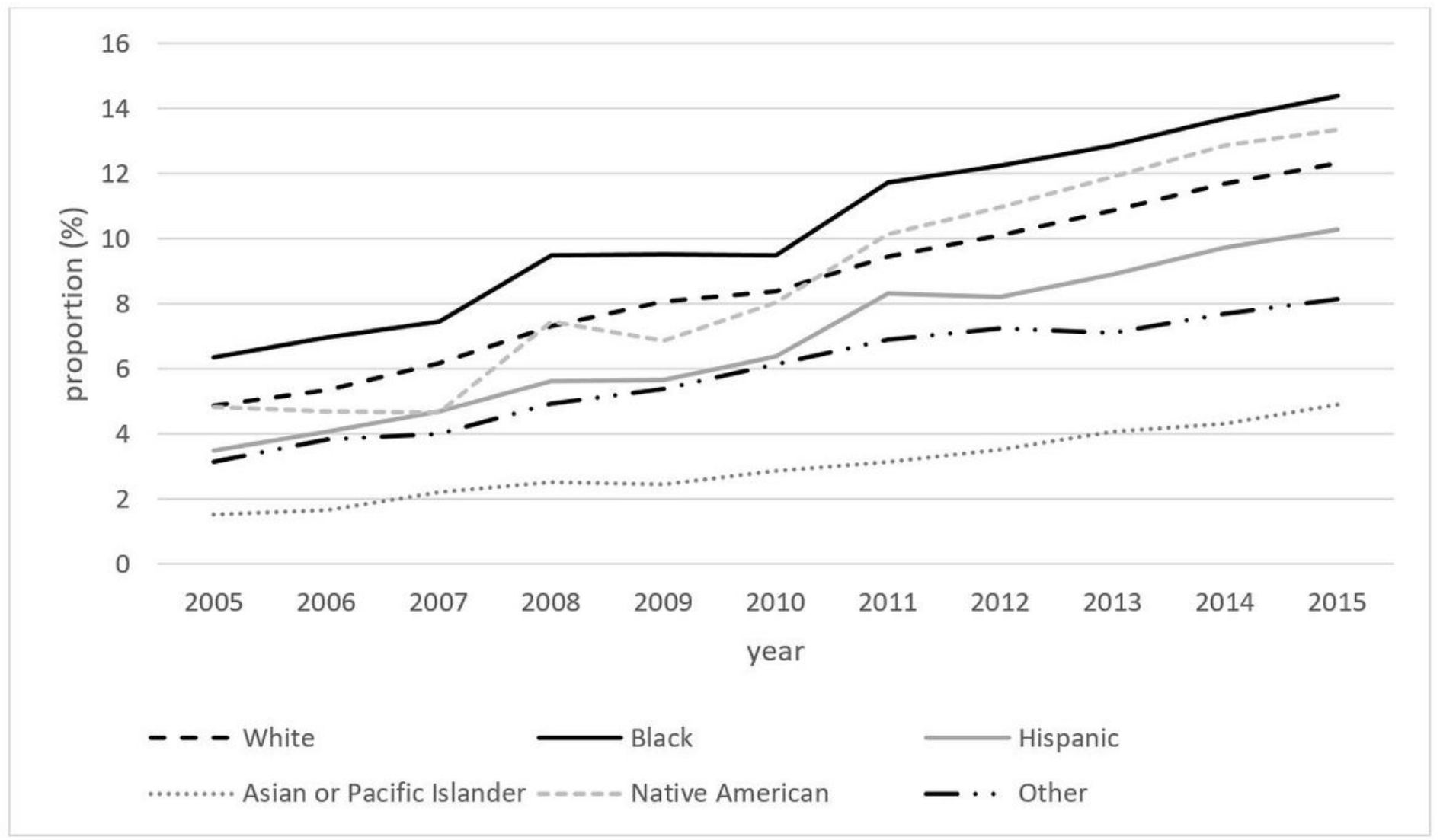

Figure 2

Trent and of obesity proportion by race among hospitalized patients in United States, 2005-2015 


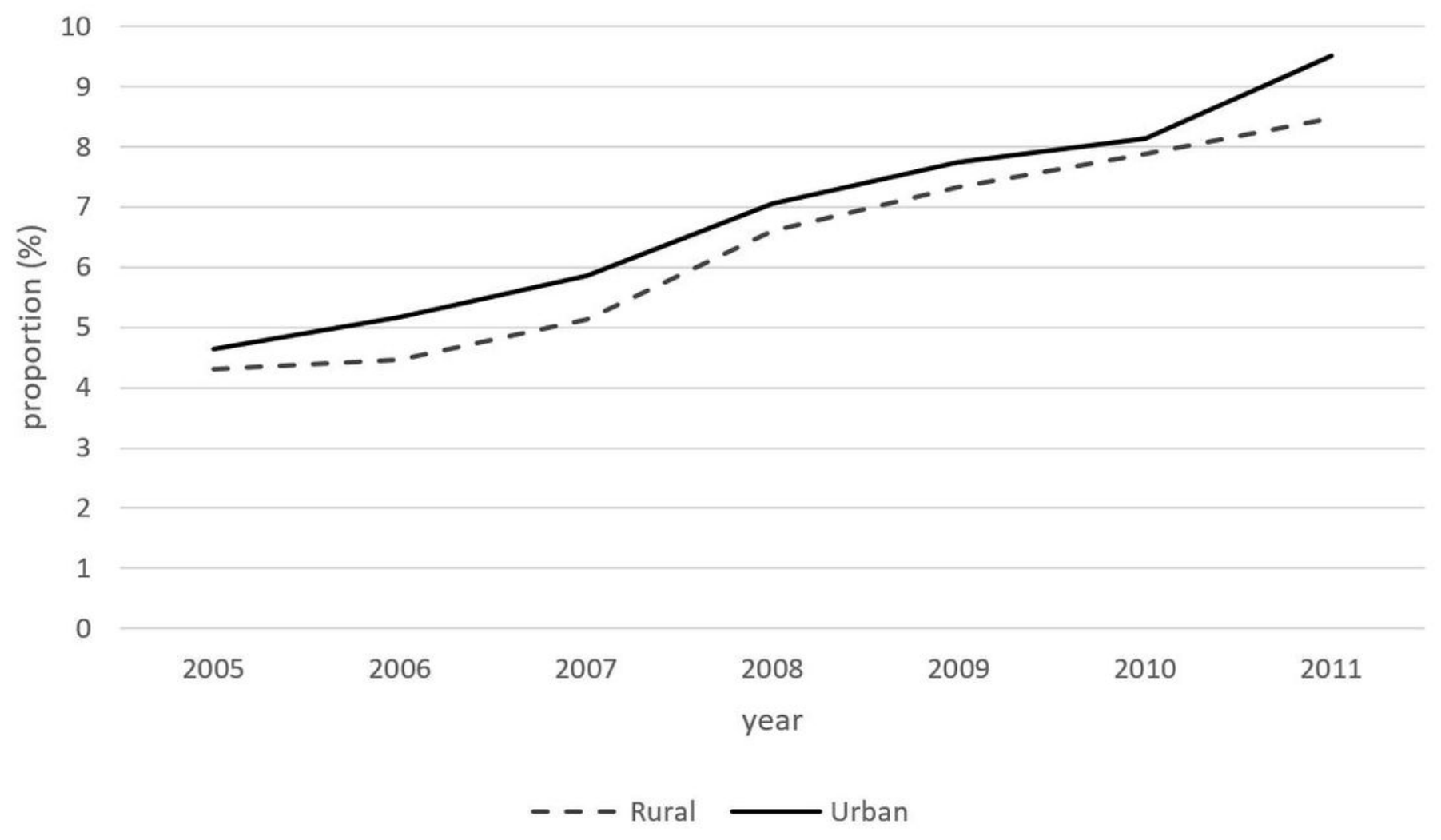

Figure 3

Trend of obesity proportion by hospital location among hospitalized patients in United States, 2005-2015

4

2

0

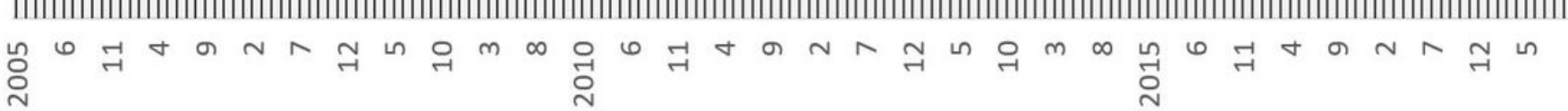

Figure 4 
Trend and forecasting of obesity proportion among hospitalized patients in United States 2005 -2025 years. 